\title{
Gêneses waiãpi, entre diversos e diferentes
}

\author{
Dominique Tilkin Gallois \\ Professora do Departamento de Antropologia - USP
}

RESUMO: A partir da releitura de registros realizados com os Wajāpi do Amapá em diferentes situações de interlocução, o artigo procura compreender a construção das diferenças a partir dos modelos nativos sobre a humanidade. As reflexões indígenas e seu manejo de marcadores de distância social são abordados enquanto "etnogênesis", no plural, enquanto processos que não se limitam à construção de identidades no confronto colonial, mas se transformam dinamicamente nos contextos de redes de relações.

PALAVRAS-CHAVE: Guianas, redes de relaçôes, narrativas, modelos nativos.

Os Waiãpi não são pobres. Porque nós temos a terra demarcada, temos floresta, temos animais, rio puro... Nós, Waiāpi, sabemos tudo e valemos muito. Nós sabemos fazer reuniōes. Sabemos fazer festas. Nós somos contadores, cantores, lutadores, brincalhōes, guerreiros. Nós, Waiāpi, sabemos fazer filhos para o povo Waiãpi não acabar. Sabemos dirigir carro, motor de popa. Sabemos manter a nossa floresta, os rios, nossas famílias. Sabemos criar filhos de animais como filhos de humanos. (Aikyry, professor, um dos autores do Livro do artesanato Waiäpi) 
Como abordar discursos como este, bem como os conteúdos utilizados para dar corpo a um coletivo, um "nós, Waiäpi", que, no contexto das relações aldeãs, não encontra realidade nem no enunciado nem na prática das relações interpessoais e intercomunitárias? Conteúdos que, quando enunciados no cenário (hoje ampliado) das relaçóes extrawaiāpi, não parecem expressar nada de muito específico, a não ser um elenco de elementos culturais genéricos que interlocutores brancos esperam ver expressos nas afirmações das identidades indígenas. As referências à luta pela terra, à capacidade de organização e à questão ambiental são parte de uma retórica que os discursos de líderes ou de professores indígenas - como é o caso Aikyry, citado na epígrafe - dispensam às platéias reunidas para ouvi-los falar dessas questôes tão essenciais à reprodução da vida indígena. Platéias essas que estão longe de imaginar o quanto é complexa a afirmação de um "nós, waiãpi" e volátil a seleção de seus traços diacríticos, remetendo a políticas que exigem negociações tanto conceituais quanto pragmáticas, as quais pretendo tratar neste texto.

Seriam esses discursos apenas afirmações contextuais e/ou "oportunistas", sem grande relevância para o entendimento da auto-imagem construída pelos próprios grupos indígenas, porque formulados no palco dos brancos? ${ }^{1} \mathrm{Ou}$, ao contrário, podem nos remeter à lógica subjacente aos procedimentos enunciativos da identidade e da alteridade, que são do interesse da etnologia amazônica?

Como, por exemplo, relacionar os recursos utilizados por Aikyry com outros enunciados que, por meio da seleção de itens culturais, lançam uma ponte identitária que aproxima os Waiāpi de outros índios, neste caso, seus vizinhos Aparai?

"Aparai é como a gente (janekwer), só que fala outra língua e as mulheres usam tanga só na frente." (Presidente do Conselho das Aldeias Waiāpi) 
Revista de Antropologia, São Paulo, USP, 2007, v. 50 No 1.

Em termos da correlação entre esses enunciados e o que nos dizem os mitos sobre a categoria de inimigo, seriam mais significativas afirmações como esta?

"Aparai fede, roubam nossas mulheres. Tem que ter cuidado, na Casa do Índio, pra não beber no copo deles. Eles são venenosos, dão veneno para nossas mulheres nunca mais engravidarem. São apã (inimigos).” (Chefe de aldeia)

Uma das entradas possíveis para as questôes que pretendo tratar aqui seria abordar as aparentes contradiçōes que se evidenciam nas várias apreciações dos Waiãpi a respeito de seus vizinhos, especialmente quando tratam de suas relações com os Wayana, Aparai ou Tiriyó, normalmente identificados como mojutapurukwer, isto é, aquela gente humana que surgiu da putrefação de Anaconda (ver item 2), cuja índole predadora os mitos explicam e que ocupa uma posição de inimigo constantemente reiterada nos diagnósticos dos xamãs de todas as aldeias waiãpi, seja na Guiana Francesa ou no Brasil.

Com base no material discursivo e de etiquetas de comportamento observadas cada vez mais freqüentemente na convivência temporária entre famílias ou membros dos grupos Wayana, Aparai, Tiriyó, Waiãpi, Karipuna, procuro problematizar aspectos da imbricação entre a política cósmica e a política humana, que tais discursos e atitudes me parecem esclarecer. A densa articulação entre representações cosmológicas e práticas das relações com os outros foi amplamente analisada na etnologia regional, especialmente por Joana Overing (1991), Patrick Menget (1985), Bruce Albert (1988) e Eduardo Viveiros de Castro (1993 e 1996), que inspiraram meu interesse e reflexão sobre a lógica waiãpi de relações com a alteridade, assim como a gestão política dessas relações. ${ }^{2}$ 


\section{Aspectos de uma rede multilocal de intercâmbios nas Guianas}

No que se segue, abordo aspectos das redes multilocais de intercâmbio e comunicação vigente na região sudeste das Guianas ${ }^{3}$ com base na perspectiva dos Waiāpi. Na primeira parte do texto, apresento um breve percurso da pesquisa, mencionando limitações nas abordagens que adotei em trabalhos anteriores, no que diz respeito às questóes de identidade aqui focalizadas. Em seguida, descrevo alguns elementos acionados pelos Waiāpi para o julgamento da diferença, no que se refere às relações que estabelecem com pessoas concebidas como parentes ou aliados, índios ou não-índios, próximos ou distantes, conhecidos historicamente ou encontrados recentemente. $\mathrm{Na}$ terceira parte, trato do uso mesclado de classificadores de distância social e de traços culturais selecionados e construídos no bojo de intercâmbios que atualmente são vivenciados principalmente na cidade - ou seja, num cenário que integra os brancos -, onde membros de diferentes grupos indígenas da região elaboram em sintonia seus discursos "étnicos".

O texto do jovem professor Aikyry, que abre este artigo, é um exemplo particularmente interessante dessa retórica "étnica", utilizada para que seja possível apresentar-se como e entre indios, diversos entre si mas também parentes. Nesse tipo de construção, a unidade de referência é uma unidade internamente indiferenciada (nós, Waiāpi) e, por esse motivo, politicamente neutra. Para afirmar coletivos como esses, recorre-se à lógica da domesticação (Gallois, 1988 e 1993), ${ }^{4}$ que, como se verá adiante, gera costumes, atitudes etc. (enfim, como dizem hoje os jovens waiāpi falantes da língua portuguesa, uma "cultura”) que podem ser compartilhados e transmitidos. Mas os mesmos locutores, em função de interesses políticos particulares a seus grupos e parentelas e independentemente da etnia a que pertençam, também fazem uso da lógica da 
Revista de Antropologia, São Paulo, USP, 2007, v. 50 No 1.

agressão (ou da predação), que, por sua vez, sustenta os discursos xamanísticos, promovendo o distanciamento e a marcação de posições e contraposiçōes políticas. Arranjos culturalistas e arranjos políticos são soluçôes alternativas, mas sempre articuladas, no jogo das relações entre os Waiāpi e seus vizinhos. São esses arranjos o objeto deste artigo.

Se os estudos das formas de socialidade e das filosofias indígenas amazônicas buscaram nas lógicas nativas os princípios que entram em ação no convívio com a diferença, fazendo desta o motor da vida social, ainda falta encontrar um foco adequado para a análise de novas formulações de tipo "culturalista" (Sahlins, 1997), que são acionadas para a delimitação de unidades de caráter étnico. O que fazer, por exemplo, com certas afirmações identitárias que parecem trazer de volta às Guianas unidades maiores que o grupo local, ou seja, de coletivos especificados por traços que, em outros momentos, são utilizados para instituir diferenças entre os Waiāpi e os Wayana, os Tiriyó etc.? Em outras palavras, o que é Tiriyó? Karipuna ? Ou Waiāpi? E em que contexto?

No caso guianês, um dos principais empecilhos para o entendimento das redes de comunicação regional foi a proeminência que a noção de "fechamento" sociocosmológico recebeu na literatura etnológica. A idéia de sociedades isoladas e fechadas sobre si mesmas dominou durante muito tempo a descrição das sociedades indígenas guianenses e tem sido amplamente apropriada pelo senso comum. Essas concepções terminam por mascarar os ricos processos por meio dos quais esses grupos se reclassificam permanentemente aos outros e a si mesmos, em gradientes altamente manipuláveis de alteridade.

O que nos interessa aqui são os modos como se constroem a aproximação ou a distância social. Se admitimos que a compreensão das relaçoes históricas e contemporâneas entre grupos indígenas na região das Guianas torna indispensável desconstruir o recorte localista e o recorte étnico, penso ser também indispensável discernir entre os produtos 
culturais e os produtos políticos da intensificação das relações intercomunitárias e interétnicas, atualmente em curso na região. São essas situaçôes, e nelas como se pensa e se efetua a passagem da distância à aproximação, bem como o trânsito de uma posição para a outra, que procuro abordar a seguir. $\mathrm{O}$ intuito é contribuir para o entendimento dos processos de fusão e fissão, tão freqüentemente mencionados na literatura regional. Como são pensados e como são vividos esses processos, e, sobretudo, em qual escala e em quais situações?

\section{Do mito à política "indígena"}

O percurso de minhas experiências interpretativas referentes às reflexões dos Waiápi sobre a convivência com os outros - membros de outros grupos indígenas ou não-índios - permitiu-me migrar de um foco centrado inicialmente nas categorias tal como postas nos mitos para o entendimento de situaçôes em que se tornava relevante um certo uso "étnico" dessas mesmas categorias. No conjunto dos trabalhos em que, entre outras questôes, me propus a analisar narrativas míticas ou históricas, diagnósticos de agressões diversas e variadas retóricas enunciadas em palcos de caráter local ou multilocal, procurei dar conta tanto das estratégias culturais em jogo quanto da dinâmica cognitiva subjacente à construção de representações de si e dos outros. ${ }^{5}$ Esses trabalhos atendiam, cada um a seu modo, ao entendimento das diferentes situaçôes históricas em que essas representações foram ativadas e manipuladas.

No primeiro deles (Gallois, 1988), construí uma apresentação da sociedade waiāpi baseada em modelos da etnologia amazônica da época, com foco na noção de pessoa e na teoria nativa da agressão e da domesticação. Os dados analisados - ou seja, o registro da enunciação das categorias de alteridade - limitavam-se aos utilizados no âmbito das 
Revista de Antropologia, São Paulo, USP, 2007, v. 50 No 1.

aldeias dos Waiãpi do Amapari. Ampliava-se, assim, um estudo anterior (Gallois, 1986), no qual, incentivada pela insistência de meus interlocutores waiãpi em marcar diferenças entre $s i,{ }^{6}$ selecionei alguns parâmetros para abordar a articulação de conflitos guerreiros, documentados pelas narrativas orais e pelos registros historiográficos, com a guerra xamânica (ou guerra invisível). Com base nas acusaçôes mais freqüentes por mim registradas, construí um gradiente que relacionava a capacidade de predação à ontologia indicada na categoria mítica de alteridade. Naquele momento, no âmbito das relaçôes entre grupos waiãpi, a maioria dos registros dizia respeito a acusaçôes contra os Aparai, Wayana ou Tiriyó (ou a quem quer que seja), invariavelmente identificados aos restos putrefatos de Anaconda ( moju, sucuriju), que, como veremos adiante, desempenha um papel fundamental na cosmologia waiãpi. Sempre referidas à Anaconda, também eram proferidas acusações contra distantes pajés waiãpi da Guiana Francesa ${ }^{7}$ ou, ainda, contra pajés de outras aldeias, tidos como tão mais poderosos quanto mais negociassem com "gente de longe". A lógica era bastante simples: quanto mais distantes, mais perigosos. Hoje, com a intensificação efetiva das relações concretas com gente antes distante, não é mais possível equacionar a alteridade de forma tão matemática e previsível.

Além disso, penso ser indispensável a constituição de um novo olhar sobre o produto dessas relações de distanciamento e/ou domesticação dos outros, levando em consideração não apenas aquelas formulações registradas por meio do estudo de sociedades concebidas como "totalidades culturais", mas também aquelas construídas nos palcos de comunicação multiétnica. Nessas situações, não é possível compreender a formulação e o uso de categorias de alteridade como produtos culturais autocentrados - do tipo "uma sociedade, uma cultura" ${ }^{8}$-, uma vez que dispomos, para a região das Guianas, não só de volumosos registros que provam a densidade histórica das redes de intercâmbio, como também 
de um conjunto de situações atuais de convivência entre membros de grupos os mais diversos. Essas situações, ainda insuficientemente analisadas, poderão nos trazer elementos de uma cosmologia compartilhada e de uma ética política regional, em que as posições são negociadas tanto em nível interindividual como intercomunitário.

Voltando ao percurso de minhas interpretaçôes do material waiãpi, experimentei outra abordagem, mais voltada para as questões da agência ${ }^{9}$ em um estudo das narrativas suscitadas pelas visitas à Fortaleza de Macapá, identificada como Mairi, o lugar mítico da criação e da dispersão do povo waiãpi e/ou da própria humanidade (Gallois, 1993a). A análise das falas referentes a esse evento (que, no início dos anos 1990, mobilizou sobremaneira os Waiãpi) completava outros exercícios, dedicados aos discursos políticos sobre e para os brancos (Gallois, 1985 e 1993b). O contexto de enunciação era essencial para o entendimento das modalidades variadas de construção de representações sobre a diferença entre grupos diversos, sobretudo quando configurava um cenário útil para a sua contraposição aos brancos.

A concepção waiãpi da relação com os brancos esboçada nesses trabalhos foi depois confrontada com uma nova experiência no processo da demarcação da área indígena, concluída em 1996. Os discursos que foram tomando forma, a partir (e dentro) desse evento, permitiram-me sugerir ser apenas neste contexto recente que os Waiápi passaram a se afirmar como um coletivo, ou seja, a existência de um "nós Waiāpi" só faz sentido a partir da apropriação de uma territorialidade limitada (Gallois, 1997 e 1999). Entretanto, se argumento ser apenas nessa situação que essa nova forma de representação poderia ser formulada e utilizada - algo como uma unidade de base territorial supralocal -, é porque tal argumento continua não iluminando o campo restante das relações que esses índios mantêm entre si, ou mesmo com os outros, como se verá adiante. 
Revista de Antropologia, São Paulo, USP, 2007, v. 50 No 1.

\section{Múltiplos conteúdos para construir a diferença}

Procuro, a seguir, contextualizar certos classificadores utilizados pelos Waiãpi nas avaliações que fazem de suas relaçôes com membros dos diversos grupos indígenas com os quais travam hoje relações relativamente intensas em Macapá e outras cidades, por ocasião de reuniōes ou da convivência de famílias de várias origens e etnias nas "Casas do Índio" daquelas cidades.

Para abordar tais classificações - e, sobretudo, os procedimentos de reclassificação dos outros também no jogo das relações multilocais que são parte do cotidiano dos Waiāpi -, é indispensável abordá-las inicialmente como postulados ontológicos próprios de uma cosmologia que pode ser acessada por meio das narrativas míticas ou das visões dos xamãs. Como evidenciaram as recentes análises sobre o fundamento "anímico" (Descola, 1996) ou "perspectivista" (Viveiros de Castro, 1996) das representações sobre a relação entre humanos e não-humanos, é evidente que as classificaçóes que dizem respeito à diferença entre os seres do cosmo, assim como as reclassificaçooes da passagem de uma posição para a outra - de "gente" para "bicho" ou de "parente" para "inimigo" -, passam pela avaliação das substâncias que lhes dão origem ou das que as fazem crescer e que podem ser compartilhadas entre todos os seres. Não é possível, inclusive, abstrair de qualquer análise sobre o uso de categorias referentes à diferença a lógica da transformação, ou seja, a teoria indígena que estabelece a capacidade dos seres passarem de um estado a outro, exigindo, desse modo, a mudança de uma perspectiva para a outra. Essas noções acerca da ambigüidade das aparências e da transformação permeiam a cosmologia dos Waiãpi e de seus vizinhos, viabilizando uma intensa comunicação e intervenção sobre os outros em âmbito regional. 
Meu esforço aqui visa, por ora, apenas constituir um elenco de termos utilizados na apreciação das relações entre Waiāpi e não-Waiāpi. Dessa forma, assumo inicialmente uma perspectiva genérica a respeito de um "todo" waiāpi, ou seja, de um ponto de vista particular dessa categoria de humanos, distinta das demais, como indica sua cosmogonia. Mais adiante, veremos que a fragmentação das experiências individuais impede que essa perspectiva de uma humanidade (que não é apenas waiãpi) seja confundida com um ponto de vista que viria a representar alguma totalidade social ou política waiápi, totalidade esta que não existe.

\section{Um gradiente para posicionar "nós e os outros"}

Nos comentários e exegeses a respeito da existência ou do comportamento de não-Waiãpi, construídos em diálogos do cotidiano entre indivíduos ou setores locais, predomina o uso da forma pronominal inclusiva, jane, ${ }^{10}$ uma categoria cujo estatuto procuro esclarecer a seguir. Se este "nós" não chega a expressar um ponto de vista sociocentrado, de um todo waiãpi, ${ }^{11}$ é, entretanto, utilizado para ordenar as diferenças percebidas entre si e os outros, distinguindo-se três posiçôes para estes últimos: ${ }^{12}$

\begin{tabular}{|c|c|c|c|}
\hline jane & jane kwer & jane anã & Janerowã \\
\hline nós & dos nossos & Como nós & diferentes de nós \\
\hline Nós, aqui e agora & Criados por nós & Aproximados a nós & Distanciados de nós \\
\hline
\end{tabular}

Os marcadores apresentados no quadro acima indicam a posição de sujeito e são utilizados para contrastar elementos que compõem momentos e locais variáveis da identidade coletiva. Veremos que, com esses termos, os Waiāpi se referem a procedimentos utilizados para a domesticação - envolvendo ou não o compartilhamento de substâncias, por 
Revista de Antropologia, São Paulo, USP, 2007, v. 50 No 1.

meio dos quais eles afirmam ter criado, aproximado ou afastado todos os demais seres ou grupos humanos.

Desde já, o que me parece importante destacar é que o uso desses termos não nos permite pressupor que o conteúdo utilizado como recurso para a diferenciação - por exemplo, para afirmar diferenças entre as posições extremas jane e janerowa - seja sempre preenchido com os mesmos tipos de elementos, que, como se verá adiante, podem ter caráter ontológico, remeter a substâncias ou focar aparências etc. Dentre as várias alternativas que podem dar sentido a essas contraposições - e que justificam as glosas que utilizo -, destaco adiante as mais correntemente utilizadas nas situações de enunciação registradas. É o contexto da relação com o outro, ou melhor, as qualidades da relação estabelecida, que é avaliado. São, portanto, esses contextos que possibilitam compreender como e quais conteúdos são eleitos para estabelecer a oposição entre nós e eles. Dessa forma, a perspectiva que devemos considerar para entender a formulação de pontos de vista sobre a alteridade não se equaciona necessariamente com os mesmos elementos - como se fossem "essências" -, uma vez que a apreciação dos conteúdos envolvidos na relação varia de acordo com o que dela se consegue avaliar ou o que dela se pode esperar. Dada essa dinâmica, penso que a abordagem perspectivista inclui necessariamente elementos relacionados à agência.

Voltando a nosso objetivo, trata-se de verificar como se constrói a aproximação ou o distanciamento em contextos relacionais sempre iluminados pelos interesses específicos dos envolvidos. Se é evidente que não será possível desenvolver, aqui, uma etnografia dos enunciados, tento descrever alguns elementos básicos de sua variação em contexto. Substâncias, aparência física e modos de vida são três conjuntos de conteúdos aos quais os enunciados costumam recorrer para o julgamento da diferença. Os dois primeiros encontram forte ressonância nas narrativas 
Dominique T. Gallois. Gêneses WaiĀPi, entre diversos e Diferentes

míticas, ao passo que o último consiste numa apreensão da transformação que a história das relações com os brancos impõe aos que foram originalmente criados como janekwer. De qualquer maneira, o que importa perceber é que esses elementos estão sempre e necessariamente imbricados nas assertivas dos Waiãpi.

\section{Diferenças no processo de nascimento e de criação}

Sem dúvida, o conteúdo mais freqüentemente utilizado para a marcação de diferenças entre os humanos parte de distinções que estão postas na origem e que os mitos relatam detalhadamente. Como expressão de uma teoria mais ampla da ontologia dos seres do cosmo (incluindo os que hoje têm aparência de animais), muitas das afirmações sobre a diferença recorrem aos elementos da gênese dos diferentes grupos humanos.

Veremos adiante que essa origem se manifesta na índole e na aparência das diversas gentes, em função da transferência de substâncias ( $\left.m \tilde{o}^{\prime} \bar{a}\right)$ das quais elas se originam (-jimó 'á wer, descende de). Mas a gênese envolve também a iniciativa e o processo de criação (reminỗ). As narrativas estabelecem apenas duas alternativas na iniciativa da criação das mais diversas gentes humanas: há, primeiro, os Waiápi (jane), que nascem antes de todos os outros, pela iniciativa e sob os cuidados diretos do criador, Janejar. Todos os outros surgem depois (sejam eles considerados janekwer, janeanã ou janerowã), como resultado da criação ${ }^{13}$ bemsucedida ou fracassada, realizada agora pelos primeiros humanos. Admite-se assim que todas essas gentes são - ou foram, em alguma medida - crias dos Waiãpi. Essa relação de criação é portanto central, pois é a partir dela que se estabelecem duas únicas alternativas de existência: 


\begin{tabular}{|c|c|}
\hline \multicolumn{2}{|c|}{ Janekwer } \\
\hline $\begin{array}{l}\text { Janejar reminower } \\
\text { (as crias de Janejar) }\end{array}$ & $\begin{array}{l}\text { jane (waiāpi) reminower } \\
\text { (crias nossas, dos Waiãpi) }\end{array}$ \\
\hline
\end{tabular}

A princípio, todas as gentes humanas foram, são ou podem vir a ser consideradas janekwer, que desponta como a categoria mais abrangente de designação do outro. É o termo utilizado atualmente para se designar genericamente todos os "índios". Veremos, entretanto, que a diversidade interna à categoria janekwer remete aos desdobramentos do processo de criação, que abre a possibilidade de desenvolvimento de gradações na alteridade. Pois a iniciativa e a experiência da criação de um outro estabelecem uma relação de proximidade que não tem necessariamente continuidade, como indicam as outras posiçóes, aludindo a diferenças que se constroem no tempo:

\begin{tabular}{|c|c|c|}
\hline $\begin{array}{c}\text { Jane } \\
\text { nós, aqui e agora }\end{array}$ & $\begin{array}{c}\text { Janerowã } \\
\text { distanciados de nós }\end{array}$ \\
\hline & $\begin{array}{c}\text { Janekwer } \\
\text { eram dos nossos }\end{array}$ & $\begin{array}{c}\text { Mojutapurukwer } \\
\text { eram dos outros }\end{array}$ \\
\hline
\end{tabular}

O que as narrativas míticas estabelecem - e que é reiterado pela maior parte dos enunciados sobre as diferenças entre as gentes humanas - são sobretudo dois processos distintos de nascimento, contrapondo aqueles que surgiram pela iniciativa do criador àqueles que brotam de processos de transformação de outros seres - animais ou inanimados -, independentemente da vontade de Janejar, mas envolvendo a intervenção ${ }^{14}$ dos primeiros humanos, como veremos a seguir.

Os Waiápi dizem que apenas eles (e algumas outras gentes que podem ser classificadas como janekwer) são descendentes dos primeiros 
homens que nasceram da flauta (jimõ' áwer), tocada pelo criador quando resolveu que precisava de companhia, porque se sentia só. Essa gente do início dos tempos nasceu muda, mas Janejar lhes deu a palavra (hoje se diz "a língua” waiãpi) e logo lhes ensinou a cultivar a mandioca e a processá-la para preparar o caxiri (bebida fermentada à base de mandioca), para que se embebedem e dancem, tocando as flautas turé que o criador continua ouvindo, mesmo de longe, já que ele resolveu ir embora.

Ressalvando-se o nascimento da flauta, esse modo de criação instaurado por Janejar prosseguiu pela iniciativa dos Waiãpi, que continuam afirmando que "criam" pessoas - pouco importando sua origem étnica - ao dispensar alimentos, muito caxiri, o ensino de sua língua e seus costumes.

Mas há "muitas gentes" que esses cuidados não lograram transformar em gente próxima. Como mencionado, trata-se de quem surge como produto residual da putrefação de cobras, e é por isso denominado genericamente mojutapurukwer, "restos da putrefação de Anaconda". Como são várias as anacondas e muitos os tipos de abelhas que botam ovos em seus cadáveres, são também imensamente numerosos aqueles que brotam dos vermes (tapuru) que cobrem as cobras apodrecidas. ${ }^{15}$ Entretanto, apesar de sua origem substancialmente distinta, essa gente não surge já distanciada. Ao contrário, eles são afastados por iniciativa das crias de Janejar.

Para explicar esse segundo processo de afastamento do outro, há um ato muito significativo a ser considerado, envolvendo uma relação entre cunhados. As narrativas contam que moças saíam para namorar às escondidas, dizendo que iam limpar suas roças; na verdade, elas nada faziam além de levar para os amados a carne caçada por seus irmãos. Intrigados com o sumiço da caça e das irmãs, eles as seguem, às escondidas, e as surpreendem namorando com belos rapazes, adornados com pinturas corporais e fartos colares de miçangas. Os irmãos decidem matar os amantes que, quando caem mortos, se transformam em cobras mons- 
truosas. Dizem os Waiãpi que, quanto mais atraente e decorada a pele do rapaz, mais temível é a cobra.

Mais uma vez, é da recusa de uma relação inadequada entre afins que surgem aqueles grupos humanos que terão de ser distanciados, agora pela iniciativa da comunidade inteira. Pois o mito estabelece que, contentes em terem se livrado dos amantes das irmãs, os irmãos voltam a caçar para alimentar os seus. Um dia, reencontram a cobra morta e percebem que sobre o seu cadáver há vermes que estão dando vida a crianças pequeninas. $\mathrm{Ou}$, então, de acordo com outras versões, voltam à beira da mata ao ouvirem o choro de crianças, e as levam para a aldeia, onde todos se empenham em criá-las. As narrativas detalham os processos de criação, que envolvem sobretudo práticas alimentares, descrevendo tipos de mingau com que as crianças são alimentadas e que as farão crescer rapidamente. Também relatam como prossegue a sua socialização, com o esforço de toda a comunidade que tenta incutir "naquela gente" modos adequados à vida tranquiila e comedida, tão valorizada pelos Waiãpi. Tudo é em vão, pois "essa gente" é substancialmente abusada e violenta e não se comporta como se espera de janereminó (nossas criaturas). Por isso, a pedido de seus criadores, os que nasceram da putrefação de Anaconda são finalmente distanciados, partindo para viver muito longe, e os Waiãpi voltam a viver em paz. Uma vez distanciada, "essa gente" se torna $a p a \tilde{a}$, inimigos que vez ou outra voltam, brigando, atacando, roubando e matando. "São assim mesmo", dizem os Waiãpi, "porque são mojutapurukwer". Esse tipo de afirmação representa bem sua teoria da diferença, que consiste em julgamentos a posteriori, em que se pode estabelecer que a índole de grupos ou de indivíduos tem relação direta com sua origem, ou seja, no caso dos inimigos associados a Anaconda, às substâncias que lhes dão vida.

Em oposição aos que foram distanciados como apãa, há muitas outras gentes que, mesmo que tenham nascido da transformação de animais 
mortos, não se tornam $a p \tilde{a}$, porque não brotaram da putrefação de Anaconda. Há os que brotaram de vermes nascidos da putrefação de bichos menos horrendos, mas mantêm com seus suportes originários alguns traços distintivos comuns, como, por exemplo, a cor da pele, o uso de certas cores e enfeites etc. Ao contrário dos primeiros, estes outros grupos humanos distinguem-se por sua aparência (ver adiante), mas sua índole pacífica resulta da aceitação do processo de criação e das etiquetas de comportamento que os primeiros homens - aqueles criados pela iniciativa e/ou nos modos de Janejar - lhes inculcaram. Por isso, são também janekwer, algo como "ex-nós": estavam juntos nas aldeias dos primórdios, mas se distanciaram, utilizam-se de outros ornamentos, de outras línguas, mas podem ainda ser chamados a ser parte de um "nós". O que é certo é que as criaturas de Janejar, como os Waiãpi se consideram, criaram ou tentaram domesticar todos os demais grupos humanos, sejam eles considerados janekwer ou janerowã. ${ }^{16}$

Os não-índios, genericamente designados karaikô, nascem de processo semelhante. Eles também são gente com origem residual, entretanto, ao contrário daqueles afins que surgem da putrefação das cobras e se tornam $a p \tilde{a}$, sua emergência nada deve à intervenção dos primeiros homens. Eles simplesmente caem do céu, na forma de pedras de diferentes cores, das quais saem criancinhas que crescem com os traços das diferentes raças - "brancos, negros e franceses". Diz-se também que eles vêm da chuva e que são tão numerosos quanto as gotas d'água, pois foi num dia de águas torrenciais que as pedras caíram. Eles são amãna rảyr, filhos da chuva. O processo de nascimento é o mesmo. Os habitantes da aldeia escutam o choro de crianças e saem para ver o que está acontecendo. Encontram pequenas crianças brotando das pedras e as levam para casa, com a intenção de criá-las. Mais uma vez, as narrativas contam detalhes a respeito do processo de criação, com ênfase nos sofisticados mingaus que deveriam fazer crescer essa gente a quem se tenta incu- 
Revista de Antropologia, São Paulo, USP, 2007, v. 50 No 1.

tir boas maneiras. Neste caso, o fracasso não se deve ao gênio violento, mas ao fato de casarem "de qualquer jeito" e jamais observarem resguardos. Por isso, dizem os Waiāpi, os karaikó geram proles inumeráveis. Para alimentar tanta gente, é preciso derrubar a mata em extensões enormes. As dificuldades da vida conjunta resultam em nova separação. Em algumas versões, diz-se que Janejar reaparece e resolve destruir todos para depois recriar a humanidade, que já aparece distinta: karaikó, parainsikó e mekoro (brasileiros, franceses e negros) já estão presentes, mas ocupando as bordas da terra e distantes das criaturas de Janejar, que voltam a ocupar-lhe o centro. Em outras versões, não há destruição nem recriação, apenas distanciamento, nas quais se diz que são as criaturas de Janejar que buscam distância e se afastam dessa gente excessivamente numerosa e destruidora. Entretanto, o procedimento pouco importa, pois o essencial é a necessidade de distanciamento, dada a impossibilidade de modificar a índole inadequada dessa humanidade residual.

\section{Diferenças na aparência e na capacidade de comunicação}

Outros enunciados sobre a diversidade entre os humanos partem de uma avaliação centrada na aparência, em vez de ter como foco a índole das pessoas. Se uma das lógicas utilizadas pelos Waiāpi para o julgamento da diferença articula tais índoles ao resultado da criação de rebentos derivados de diversas substâncias, outra lógica deixa de focar os comportamentos para considerar os traços físicos, também atrelados às substâncias de que se originam. Trato a seguir de múltiplos enunciados em que são utilizados critérios que distinguem o porte (há altos e baixos), a cor da pele (há escuros e claros), a força física (há fortes e fracos), além de outros elementos que destacam o gosto pelo uso de determinados enfeites, como penas no nariz ou nas orelhas, o corte de cabelo etc. A aplicação desses critérios permite apreciar e classificar todos os humanos, ou 
seja, todas as raças e todas as marcas étnicas possíveis que chegam, seja como for, ao conhecimento dos Waiāpi por meio de encontros, imagens ou relatos. De negros com cabelos enrolados a japoneses com cabelos semelhantes aos dos índios, de grupos indígenas cujas mulheres andam nuas àqueles em que elas usam tangas etc., não existem limites, nem no espaço nem no tempo, para distinguir entre "gente nossa" e "gente outra", entre jane e janerowã, inclusive dando forma a uma espécie de teoria racial waiāpi.

Os classificadores que são utilizados para dar conta de tantas diferenças estão, sem dúvida, postos na mitologia, mas é no contexto de cada encontro que se recorre à capacidade criativa de cada um para operar distinçōes. Há modas interpretativas como também há modas no uso de nomes de brincadeira, e é assim que se faz apelo a novos critérios para julgar aparências. Esses podem ser apropriados por terem alguma relação, mesmo que tênue, com as marcas físicas da diferença, por serem enunciados em alguma experiência anterior e reavaliados nos comentários que circulam nos pátios das aldeias. Foi assim, por exemplo, que os Waiãpi do Oiapoque, quando assistiram a imagens em vídeo de rituais kaiapó com pintura no rosto e porte de bordunas, associaramnos aos Apaches dos filmes de bang bang, que estavam mais acostumados a reconhecer nas telas de TV de suas aldeias. Essa interpretação circulou durante um certo tempo entre muitas aldeias waiāpi (sendo inclusive "exportada" para outras aldeias no Brasil, onde se começou a apreciar filmes de faoreste) para sinalizar a valentia desses grupos no ataque aos brancos.

Os julgamentos que distinguem os humanos com base em sua aparência são constantemente contraditos em novas experiências, fazendo deslizar certezas para dúvidas e estas para uma nova certeza e para a atribuição de uma nova posição. Assim, durante muito tempo, nas aldeias waiāpi do Amapá, os Kaiapó foram classificados como janerowã por- 
que usavam enfeites labiais, ou seja, furos e deformações no rosto considerados feios. ${ }^{17}$ Depois da visita de alguns Waiãpi aos Zo'é (em 1992) e dos Zo'é aos Waiãpi (em 1996), variadas evidências de proximidade nos costumes fizeram que estes Tupi do Cuminapanema - que também usam enfeites labiais e persistem na nudez - fossem classificados como janeanã, ou seja, gente com a qual se pode conviver (ver abaixo). A experiência com os Zo'é fez que, durante um certo tempo, os Waiãpi privilegiassem enunciados que ocultavam a feiúra de tais deformações e furos (além da nudez que tanto os incomodava), fazendo que até outros grupos que lançam mão de tais deformações (inclusive os Kaiapó) fossem anunciados como janekwer, um termo que hoje é traduzido como parente. Mas não durou muito. Dois anos depois, durante um encontro pan-indígena em Brasília, voltaram atrás, depois que alguns Kaiapó arrancaram o microfone das mãos dos representantes waiāpi: a índole agressiva dos Kaiapó falou mais alto, e a maior parte dos Waiápi voltou a enunciá-los como janerowã. Como se vê, a aparência não diz tudo. Como se sabe, ela pode esconder índoles ontologicamente distintas.

Acredito que um dos modelos nativos para pensar a diferença de aparências seja o da gênese dos subgrupos waiãpi, que é narrada com foco nos traços físicos que distinguiam esses grupos entre si. Se todos saíram das flautas tocadas pelo criador, seus traços físicos são diferentes porque nasceram de flautas feitas com matérias-primas diversas: tipos de palmeiras, canas de flecha, taquaras etc. Ao sair ou descer (como se pode glosar jimõ'á wer, descendente) de espécies vegetais diferentes, eles carregam traços físicos próprios. Há os que nunca têm cabelo branco quando envelhecem porque saíram da flauta feita de madeira marajayr. Há os que têm muito cabelo porque nasceram da flauta de madeira wiri. Os que vem do toriri morrem jovens porque essa madeira é mole e não dura muito, ao contrário de quem veio da flecha e não morre cedo. E assim vão se seguindo as descrições, associando características da maté- 
ria-prima vegetal utilizada nas flautas ou nas armas ao físico dos humanos (ver Gallois, 1993, pp. 67-70). Enquanto me contava tudo isso, Kumai, um líder emergente entre os Waiãpi, acrescentava: "E aí Waiãpi vai misturando, misturando tudo, todos. Nós casávamos com outros índios, por isso é que tem tantos índios, vieram de não sei o quê e o quê, até porque eu não sei quantos índios diferentes têm no Brasil" (ibid.). Esses que se misturam, "entre índios", são todos abrangidos pelo termo janekwer, "ex-nós", que pode ser considerado como uma primeira acepção do termo português parente, utilizado hoje para designar "os índios”. Em inúmeros contextos, aplica-se esse critério para generalizar a mistura e, portanto, a semelhança e a proximidade (nas aparências) de todos os índios entre si, usando-se como artifício a referência a essa lógica da etnogênese e da origem. Mas esse foco na aparência ou nas qualidades físicas não se confunde com o julgamento de índoles diferenciadas, que permitem voltar a julgamentos relacionados aos aspectos substanciais que presidem ao surgimento ou à criação de "cada gente". Aí sim, sempre, mantém-se a diferença entre aqueles que brotam de cobras putrefatas e aqueles que nascem dos diversos tipos de flautas (de toda forma, de vegetais), qual seja, entre gente agressiva e gente pacífica.

É claro que, hoje em dia, com as novas oportunidades de se conhecer gente de longe, apreciada ao vivo ou por meio de imagens, outros elementos vêm imbricados nas classificações. Entre eles está a língua, ou seja, a capacidade de interlocução, que leva, por exemplo, os Araweté ou os Asurini - ouvidos e conhecidos por meio de vídeos -, ou os Tembé - encontrados na Casa do Índio em Belém - a serem protótipos de janekwer, descendentes dos primeiros humanos criados pela vontade de Janejar.

Usar as mesmas palavras para as mesmas coisas, especialmente para alimentos e processos culinários, também é considerado pelos Waiãpi como um indicador de proximidade no tempo das origens. Mas, da 
Revista de Antropologia, São Paulo, USP, 2007, v. 50 No 1.

mesma forma que as aparências, os pressupostos sobre as substâncias que dão origem às pessoas, às vezes, podem "enganar" (Rivière, 1995). Do mesmo modo, as apreciações que os Waiãpi formulam sobre a proximidade entre gente diferente podem ser alteradas com o desenrolar de experiências de convivência. Não se trata, portanto, de pensar a diferença como algo dado a partir de "essências", mas como algo que se transforma por meio da "troca de substâncias", que, até certo ponto, são passíveis de mistura, como indica o rico código culinário presente nas narrativas míticas.

\section{Proximidade no estilo de vida, foco na possivel convivência}

Em sua múltipla experiência de encontros com outros índios, além dos marcadores já indicados, os Waiāpi estabelecem distinções que focam modos de viver, qualidades do habitat etc como determinantes para julgar se é possível, ou não, conviver com gente diferente. É com esses critérios que se preenchem conteúdos da categoria janeanã, utilizada para designar gente com quem os Waiāpi já conviveram ou com quem consideram que poderiam co-residir. Nunca obtive esclarecimentos suficientes para compreender a etimologia desse termo e, em todas minhas tentativas, os Waiãpi sempre lançaram mão de uma imagem muito forte de "gente dormindo junto", numa mesma casa, com suas redes amarradas bem perto umas das outras. Janeanã são todos aqueles com os quais é possível se aproximar assim, sem risco. A inclusão de pessoas ou grupos nessa categoria se faz a partir de conteúdos variados, relacionados à boa índole, às boas maneiras - que hoje enfatizam sobretudo o habitar na floresta. Todos os que compartilham essa sabedoria, como a de construir um tapiri na mata, montar um moquém, amarrar redes, aquecerse no fogo, são ditos janeanã. Assim foram tratados os Zo'é, por ocasião da expedição de caça e pesca durante a qual os Waiãpi e seus hóspedes 
compartilharam o mesmo fogo e a mesma comida em acampamentos construídos em sintonia tanto de técnicas como de atitudes. Esse sentimento de compartilhamento de costumes não ocorreu na convivência com os Yanomami, na experiência de um jovem Waiápi que visitou e passou algumas noites em uma aldeia desse grupo e ficou impressionado com a diferença nos modos de conforto nas moradias, comentada em mínimos detalhes, como a forma de amarrar as redes, colocar a panela no fogo etc.

Hoje, com as crescentes oportunidades de conhecer e julgar modos de vida de muitos grupos indígenas, os Waiãpi passaram a usar um qualificativo que distingue aqueles que vivem como eles, em aldeias abertas na floresta, dos outros, que vivem como os não-índios, em casas ou aldeias que consideram parecidas com as cidades. Identificar-se mutuamente como ka'apor, gente da floresta, é uma das primeiras preocupações dos representantes waiãpi que participam de reuniões pan-indígenas, especialmente por ocasião das enormes reuniōes como aquelas organizadas pela Coordenação de Organizações Indígenas da Amazônia (COIAB), que aproximam um número e uma diversidade de representantes indígenas antes jamais experimentados pelos Waiāpi (e por muitos outros grupos). Nesses encontros, os Waiāpi buscam aqueles que demostram ser ka'apor como eles para escolher companhia durante as sessões, as refeições, as conversas e a dormida. E, quando voltam, vêm contando quantos káapor conheceram e quantos outros já são karairomó, gente que "virou" branco. Cabe ainda ressaltar que essa oposição me parece estar adquirindo um caráter temporal muito interessante, em que ser da floresta é como que uma origem comum a todos, ao passo que ser como os brasileiros é um destino. E, se considerarmos que tanto a proximidade quanto a distância são manejadas por meio de hábitos, como a capacidade de viver na mata ou de compartilhar determinados alimentos, há, de fato, uma série enorme de elementos disponíveis para distin- 
guir entre esses tantos e diferentes "índios do Brasil", aos quais se referia Kumai páginas atrás.

Penso que a lógica subjacente a esse tipo de classificação está expressa, como as demais, nas narrativas míticas que discriminam experiências fracassadas ou bem-sucedidas de se criar pessoas, usando-se comidas adequadas. Entre os que são considerados ka’apor, há gente mais próxima, que descende daqueles primeiros "outros" humanos, criados pelos descendentes de Janejar no começo dos tempos. Por terem sido alimentados com requintados mingaus e bebidas fermentadas, essa gente continua até hoje comendo o que os Waiãpi comem, dormindo como eles dormem etc. Enfim, são realmente janekwer pela capacidade demonstrada de convivência apropriada, a que a expressão janeanã também remete.

\section{O manejo das diferenças em redes multilocais}

Formas de nascimento e de criação (teoria ontológica), distinções de aparência (algo como uma "teoria racial") e de modos de viver (constataçooes em experiências históricas de convivência) foram até aqui descritas como três recursos utilizados pelos Waiãpi para dar conteúdo a seus julgamentos sobre os outros. Falta agora verificar como esses conteúdos são manipulados no contexto concreto dos encontros. $\mathrm{O}$ que se deve ressaltar, mais uma vez, é que a identificação de proximidades ou distâncias é realizada caso a caso, por meio de relaçôes que se desenvolvem entre indivíduos, famílias ou pequenos grupos. Mais precisamente, se consideramos que classificadores de alteridade e de identidade merecem destaque, é porque eles são forjados e utilizados no âmbito de uma ampla rede de relações multilocais. Nunca são o produto de avaliações que envolvem o ponto de vista de uma totalidade sociopolítica ampla. ${ }^{18}$ Não há uma posição "dos Waiāpi” sobre os outros, nem eles consideram 
que seus vizinhos tenham um ponto de vista único sobre eles. Toda vez que se procura alguma coerência nos julgamentos sobre sua relação com os outros, encontram-se apenas divergências, como ilustram os comentários a seguir, proferidos por pessoas que voltavam na mesma época de Macapá e estavam reunidas na mesma aldeia:

“Os Aparai são nefastos, são mojutapurukwer.” (Asi)

"Os Aparai são Waiãpi, foram criados por nós, descendem dos nossos.

Tiriyó é que é apã, come gente, perigoso.” (Rt)

"Aparai é índio, só que as mulheres usam tanga só na frente." (Ark)

Opiniōes contraditórias, resultando de experiências sempre individuais, são eventualmente (mas nem sempre) reavaliadas em um nível mais coletivo, quando se comentam fundamentos expressos nas narrativas míticas acima mencionadas, que servem para qualificar alguém ou algum grupo como janekwer, janeanã ou janerowã. Teríamos ali um caminho seguro - uma representação coletiva - para compreender as distinções que os Waiãpi enunciam nos contextos acima mencionados? À primeira vista, esses elementos são efetivamente ativados para distinguir aqueles que se comportam como possíveis parentes daqueles que não o são, porque nasceram ou viraram janerowã, gente que se deve manter a distância, como fizeram os antigos com sucessivos grupos declarados inimigos, ou apã. Entretanto, verifica-se que os julgamentos fazem uso de múltiplos conteúdos, constituindo interpretaçôes nas quais, por exemplo, nem sempre a avaliação da feiúra ou da agressividade corresponde à distinção entre parentes e não-parentes. Por esse motivo, é preciso, agora, verificar se os critérios aos quais os mitos ou visões dos pajés recorrem também intervêm na construção da noção de parente, tal como vem sendo utilizada nas redes multilocais em que os Waiãpi estão inseridos. 
Revista de Antropologia, São Paulo, USP, 2007, v. 50 No 1.

\section{Janekwer ou parente?}

Dizer que os Araweté são parentes, como também o foram por um tempo os Asurini, é constatar proximidades diversas na aparência, na língua, além de semelhanças no modo de vida significativas para criar uma identificação. Seria essa constatação equivalente aos enunciados em que se trata os Kaiapó como parentes, sabendo-se que os Waiápi os julgam tão diferentes? E como não mencionar que, no início dos anos 1980, os Asurini foram remetidos à posição de inimigo e responsabilizados por uma morte, quando se soube que seus pajés dominavam espíritos tão agressivos como os do porco-queixada? A instabilidade das apreciaçôes a respeito dos Yanomami também vale ser mencionada, já que todos os Waiāpi ouviram falar deles e chegaram a conhecer alguns de seus representantes por ocasião de visitas recíprocas. A princípio, os Yanomami também são janekwer, por sua evidente capacidade de viverem como ka’apor, e, por isso, tratados como parentes. Entretanto, já mencionamos que essas experiências de intercâmbio levaram a seu distanciamento, ressaltando-se costumes que fazem deles "gente outra", janerowã, e julgamentos de que os Yanomami não poderiam ser "criados" como janekwer.

Seria, então, o termo parente uma afirmação oportunista, a constatação de uma identificação superficial, apropriada, do discurso e no palco dos não-índios? Não teria, portanto, nenhuma conexão com a lógica a que os mitos e os diagnósticos dos xamãs recorrem para distinguir humanidades diversas? Seria esse enunciado pouco esclarecedor da teoria nativa sobre a vida social, constituindo um classificador reservado a situações que seriam "novas"? Seriam, enfim, essas afirmaçōes fake? Penso que o uso do termo em português não remete a outra lógica senão a mesma utilizada para justificar o termo em Waiãpi, pois não há uma lógica "tradicional" e outra "nova", uma "verdadeira" e uma "falsa". Mas, se os Waiãpi continuam encontrando justificativas múltiplas e criativas 
para posicionar povos vizinhos e historicamente relacionados, como os Aparai, Tiriyó ou Karipuna, também os longínquos Asurini e Yanomami, como representantes emblemáticos do outro, perigosos agressores, por que os tratam como parentes ou como janekwer?

\section{Diferentes temporalidades e espaços fragmentados}

A escolha e o uso profuso do qualificativo parente nas atuais relações entre os Waiãpi e outros índios me parecem indicar a perenidade de uma lógica recorrente em sua filosofia e experiência sociopolítica, assim como a de outros grupos das Guianas, que não viabilizam pontos de vista sociocentrados, nem no tempo nem no espaço.

Categorias de diferença são manipuladas contextualmente, sendo necessário distinguir entre as situações que remetem a temporalidades largas e espaços expandidos e outras que se processam em tempos curtos e espaços compartilhados. Afirmaçôes de distância ou proximidade não poderão ser reavaliadas da mesma maneira nesses diferentes contextos. Por exemplo, incluir os Araweté na categoria do "nós", por meio de julgamentos não comprovados pela convivência efetiva, mas apenas por identificação visual (que não deixa de ser densa, dada a carga de emoçóes em jogo nessa forma de comunicação), não significa que a posição desse povo não poderá ser alterada em outro momento, como ocorreu nas sucessivas revisões da posição dos Kaiapó, de parente para não-parente, e inversamente. Dessa forma, poderíamos nos perguntar se estamos diante apenas de um efeito da acumulação de experiências que, quanto mais individuais, mais rapidamente são desfeitas, como sugerem as opiniōes divergentes a respeito dos Aparai, Tiriyó ou Karipuna, cujos encontros com os Waiāpi vêm cada vez mais se intensificando.

Ora, a reavaliação funcional das categorias na prática depende da capacidade de agência, não apenas dos Waiãpi, mas de seus interlocutores. 
Revista de Antropologia, São Paulo, USP, 2007, v. 50 No 1.

É por isso que considero que se deva distinguir entre espaços sociais e temporalidades diversas, ou seja, entre avaliaçōes proferidas a respeito de uma temporalidade e um espaço amplo (não ver nem conviver) e aquelas enunciadas com base nas relações de convivência efetiva, dependentes de experiências variadas, numa temporalidade curta (ver e conviver). Evidentemente, afirmações sobre gente com quem nada se troca serão necessariamente mais duradouras que apreciações a respeito de gente com quem se tem inúmeras e variadas experiências de intercâmbio. E é por esse motivo que as definições postuladas nas narrativas míticas ou históricas, que tratam de eventos passados, não são um recurso suficiente para a compreensão de uma teoria da alteridade e da identidade.

Em trabalho anterior, analisei narrativas que surgiram no contexto das estadias dos Waiãpi em Macapá, no início dos anos 1990, quando julgaram ter reencontrado, na Fortaleza de São José, seu lugar (mítico) de origem, passando a chamá-lo de Mairi (Gallois, 1993). Foi nessa época que alguns deles tiveram encontros com pessoas que se diziam descendentes dos índios Tukuju (tukuju jeapyrer), antigos habitantes do lugar. Os Waiãpi trataram de recuperá-los simbolicamente como mais um de seus grupos formadores, para complementar e consolidar um discurso segundo o qual eles ocupariam hoje uma última área de refúgio nas cabeceiras do Rio Amapari, empurrados pelos brancos. Esses teriam se apossado da casa Mairi, onde o criador Janejar havia abrigado seus antepassados do cataclisma que eliminou a primeira humanidade. Nesse trabalho, argumentei que Mairi e Tukuju são "imagens do passado", recuperadas em forma de exegeses, em que a rememoração de eventos que vêm declaradamente do passado constitui uma reinterpretação de caráter etno-historiográfico. Se, de fato, uma versão mais ou menos coerente sobre Mairi e Tukuju propagou-se entre todas as aldeias do Amapari, é porque se tratava de elementos emblemáticos, tanto na memória da tradição de todos os grupos locais quanto porque eram passí- 
veis de comprovação generalizada. Todos os Waiãpi que iam a Macapá podiam visitar a Fortaleza e rememorar os antigos que por ali passaram. Da mesma forma, o encontro com karaikô, que se dizem descendentes de índios, também pode ser experimentado por qualquer um em conversas com muitos macapaenses que se orgulham dessa ascendência, sem que a natureza desses emblemas seja colocada em risco. A multiplicação dos encontros apenas reitera a veracidade do passado. Mairi e descendentes de Tukuju não agem, não trocam, ou seja, não possuem poder de interferência. Eles apenas existem.

Ao contrário das considerações sobre monumentos que remetem a origem ou pessoas com as quais não se pode trocar ou não se troca mais (mas que constituem uma reserva simbólica eficaz para construir um passado), os comentários menos elaborados - mais imediatistas mas muito mais difundidos - a respeito das experiências individuais de convivência com representantes de grupos indígenas vizinhos trazem um altíssimo grau de contradição. São discursos que não podem (e que nem interessam) ser analisados em seu conjunto, como se fosse possível extrair da reflexão de cada um uma configuração "atual" do pensamento waiāpi sobre os outros, ou o conteúdo recorrente de um gradiente preexistente que poderíamos encontrar nas narrativas míticas relacionadas à alteridade. Tal variabilidade remete a uma característica da sociabilidade guianense, que nunca se postula nem age como um todo coerente e, sim, na forma de redes de relaçóes. ${ }^{19}$ A multiplicidade de enunciados sobre os outros, proferidos em redes descentradas, ilustra a fragmentação das experiências que, ao invés de fechamento, têm como resultado uma notável abertura para o mundo. 
Revista de Antropologia, São Paulo, USP, 2007, v. 50 No 1.

\section{Criar, transformar e apaziguar - uma possibilidade permanente}

A proximidade - seja ela promovida por troca de substâncias ou em contato superficial - não é uma posição ontológica definitiva. É o produto de um intercâmbio agenciado. Recentemente, ouvi um velho Waiãpi discorrer sobre a longa estadia na Casa de Saúde Indígena em Macapá. Ele dizia ter se tornado parente de duas famílias aparai, compartilhando o espaço reduzido de um dormitório, dividindo a parca alimentação oferecida ou barganhada juntos de vizinhos, trocando histórias, cantos e receitas. Ele, um respeitado pajé, voltava para casa seguro de ter criado laços com essa gente de quem tinha se aproximado.

"Para mim, Aparai deixou de nos atacar. Quem é apã são os Kaiapó. Eles são agressivos mesmo, são assim mesmo.” (Stm)

Se, na relação de proximidade, esse velho soube criar laços com aquelas famílias aparai, o mesmo não pode ser dito dos longínquos Kaiapó. Por esse motivo, diz-se que eles são "assim mesmo", ou seja, como também dizem os mitos, a princípio, eles são agressivos porque descendem de Anaconda. Somente a princípio, já que, por meio de experiências sempre renovadas de criação e domesticação, há sempre a possibilidade de se alterar a índole de uma pessoa.

Os índios Aparai, Tiriyó e de outros grupos que os Waiāpi encontram em Macapá agem nesse sentido. Pode-se aproximar deles ou não, construindo com eles, ou não, relaçóes "de qualidade". ${ }^{20} \mathrm{Na}$ verdade, o que as dissonantes experiências de relações entre Waiãpi e membros desses grupos vizinhos indicam é que o processo de criação é pensado como fundamentalmente aberto, correndo fora do âmbito de relações etnocentradas, ou melhor, fluindo no espaço da "autonomia pessoal" (cf. Overing, 1991). 
Penso que um dos elementos mais significativos desse sistema relacional aberto, característico da vida social na região das Guianas, é a relação de parceria de troca: panary, em waiãpi, pawana (e variantes), nas línguas caribe. As relaçôes que unem determinados indivíduos ou famílias de um grupo a outros indivíduos de outro grupo, visando trocas reservadas, só podem ser mapeadas na forma de uma rede, quando se tem acesso à perspectiva de cada um. Perspectivas que só podemos encontrar entre os que compartilham da relação de parceria, construída no nível interpessoal e considerada um assunto particular. $\mathrm{O}$ mesmo ocorre na relação estabelecida entre Aparai, Tiriyó, Karipuna, Waiãpi, que podem se criar mutuamente por meio de relaçôes adequadas, hoje concebidas como o trato esperado entre parentes.

Pois criar o outro é também criar a si mesmo. Trata-se de uma experiência reflexiva, segundo a qual, se posso criar o outro como parente, eu mesmo posso ser criado como outro. Um episódio em curso na área waiāpi não diz outra coisa: são as constantes ameaças de morte que uma parte das aldeias profere contra uma família que se aproximou demais de xamãs associados a um grupo distanciado como inimigo, indo, até mesmo, morar com eles em aldeias distantes onde, com certeza, "viraram" outros.

A rede de relações interindividuais que afasta quem é julgado outro, ou aproxima quem é criado como parente, exige que se revise o caráter supostamente "coletivo das representaçôes coletivas", como sugere Hannerz (1992). Pois, nesse contexto de relações em redes abertas, "o que são construçôes individuais e o que se recebe em transmissão, talvez no final, façam alguma diferença" (id., p. 42). O que nos leva a afirmar que o resultado da circulação de construções e interpretaçôes individuais, no bojo dos canais de transmissão coletiva, não faria diferença somente se as sociedades guianesas fossem mônadas fechadas e fóbicas em relação ao exterior. 
"Waiāpi não sei o que é [...] mas, coletivo, nós só tem na família, na roça” (Trk)

Resta-me voltar às afirmações de tipo culturalista (cf. Sahlins, 1997), reproduzidas no início deste texto. Apresentar-se como "nós, Waiāpi", "nós, gente da floresta", "nós, índios" são experimentos que abrem espaço para o contínuo exercício de julgamentos sobre a diversidade e a diferença (cf. Bahba, 1998). Eles se tornam particularmente interessantes se, em vez de os interpretarmos como identificações (étnicas) que fecham ou excluem, os entendermos como ditos para abrir conversas, viabilizar novas relações. Postular, entre índios, que são todos possíveis parentes só pode ser feito com base em elementos genéricos como aqueles - ser cantador, dançarino, caçador etc. Ou seja, a partir de caracteres suficientemente abrangentes para abrigar a todos e para permitir que, cada um por si, possa agir como deseja.

O desafio que se coloca hoje aos índios, submetidos e constrangidos por nossas idéias a respeito das unidades que eles supostamente representam e por instituições que pretendem configurá-los como coletivos, é encontrar elementos para atender a essas demandas sem que precisem abdicar de suas filosofias sociais.

São essas consideraçôes que me levam a reiterar o quanto, para os índios das Guianas, são significativos os classificadores de aparências, que abrem ao infinito as apreciações sobre a diversidade humana, permitindo a produção de identidades genéricas, entre gente que usa ou não usa tembetá, cabelo curto ou longo, tanga completa ou tanga só na frente. Dizer que, sendo "Waiāpi” ou sendo qualquer "índio", se é bom cantador e bom caçador é apelar para o mesmo recurso. São elementos culturais negociáveis entre todos. Já aqueles elementos feitos de substâncias que os grupos das Guianas sabem poder manipular cuidadosamente, por meio de relaçôes mais particulares, estes não são generali- 
Dominique T. Gallois. Gêneses WaiĀPi, entre diversos e Diferentes

zados, pois determinam a gestão de relações propriamente políticas. O manejo de aspectos ocultos da pessoa do outro, que podem ser modificados ou alterados por meio de processos de domesticação ou de agressão, promove o intercâmbio de substâncias que afetam a relação com esses seres. São essas as modalidades mais significativas para a gestão das relaçōes de poder, ou seja, as relações políticas. São feitas dessas substâncias as relações que fazem a diferença. Ao contrário, como apontamos acima, classificadores moldados sobre a diversidade de traços são altamente negociáveis, "abrem" conversas. Se elementos culturais se negociam, não será da mesma maneira que se negociam relações de poder nem a gestão do político, que continuam necessariamente fragmentadas, fusionando ou cindindo grupos.

\section{Notas}

1 Que abrange cursos de formação de professores e agentes de saúde indígenas, reuniões pan-indígenas promovidas por instituições diversas, convivência nas casas da Funai e da Saúde, na cidade de Macapá /Amapá, que se configura há cerca de dez anos como um "pólo de articulação interétnica" (cf. Melatti, 1997). É também nesse palco que surgiu, em 1994, o Conselho das Aldeias Waiãpi, também denominado Apina (nome de um subgrupo waiāpi rememorado por sua valentia), em que os jovens vêm ocupando um espaço crescente.

2 Que prefiro não definir como "relações exteriores", como sugeria Menget (1985), dada a ambigüidade da fronteira entre relaçôes "internas" e "externas", como se verá adiante.

3 As questões deste texto são temas da Pesquisa Temática "Sociedades indígenas e suas fronteiras na Região Sudeste das Guianas", voltada ao estudo das redes de relaçôes que os grupos daquela região mantêm entre si, que nos propomos configurar focalizando seu caráter multilocal, verificando como são interpretadas pelos diferentes grupos estudados (Waiwai, Wayana, Aparai, Tiriyó, Kaxuyana, Zo’é, Waiāpi, Karipuna, Galibi e Palikur), com base em esquemas sociocosmológicos 
Revista de Antropologia, São Paulo, USP, 2007, v. 50 No 1.

amplamente compartilhados na região. Leva-se ainda em conta o fato de que essas redes de comunicação são potencializadas pelo intercâmbio de concepçôes acerca do "ser índio" e das diversas experiências que esses grupos mantêm com agentes do contato desde o período colonial.

4 Ressaltando-se diferenças significativas entre essa lógica de domesticação e a de "predação familiarizante", recentemente analisada por Fausto (2000).

5 Como recomenda Albert (1988).

6 O que se pode sempre confirmar por meio do intenso jogo de acusaçôes de agressão entre xamãs representando facções locais waiãpi, tanto no Amapari como no Oiapoque.

7 No discurso acusatório que o diagnóstico representa, costumava-se atribuir, aos xamãs waiãpi que vivem no distante Oiapoque (Guiana Francesa), "mestres" aparai. Essa justificativa vigorou especialmente quando os Waiāpi do Amapari constataram que algumas famílias wayana e indivíduos aparai estavam se instalando nas aldeias do Oiapoque.

8 Visão durkheimiana que Hannerz critica, por sua aplicação limitada aos raros contextos de "prototypical small-scale society, in which people exposed to much the same living conditions have similar personal experiences and are at the same time available to a massively redundant communication flow only from people like themselves" (1992, p. 42).

9 Refiro-me aqui tanto à abordagem de Sahlins (1990) a respeito da reavaliação funcional das categorias na prática quanto à de Barth (1987), que recomenda diferenciar a tradição recebida de sua reprodução, permitindo a expansão de nossa compreensão de uma tradição e de uma cosmologia "not by constructing more order in it, but by better accounting for its production" (1987, p. 84).

10 Note-se que, nesses comentários e contextos - mesmo na presença ou em conversa com um interlocutor que não faz parte do grupo -, usa-se o pronome inclusivo (jane) e não a forma exclusiva (ore), que nunca é utilizada em afirmaçôes como essas. Os Waiāpi só utilizam a forma exclusiva para se referir ou descrever açôes: "nós estamos cansados (e vocês não)", "nós estamos partindo (e vocês não)" etc. Assim, quando se apropriaram de uma noção de "terra" para seu uso exclusivo e para afirmar a existência de limites entre sua área de ocupação e a dos brancos, os Waiãpi passaram a utilizar a expressão jane yvy, uma categoria que não expressa apenas a distância ao outro, mas a afirmação de uma perspectiva sobre esse limite. 
Dominique T. Gallois. Gêneses WaiĀPi, entre diversos e Diferentes

Terra é outro contexto em que o pronome exclusivo nunca é usado, pois a expressão ore yvy remeteria a posiçôes diferenciadas internamente aos Waiãpi, uma diferenciação que não faria sentido nesse contexto (ver Gallois, 1999).

11 Retomo adiante a distinção entre o uso dessas formas pronominais e de categorias discursivas que remetem a construçôes culturais (ou étnicas) que estão se afirmando hoje como úteis ao agenciamento de relaçôes cotidianas, dentro ou fora das aldeias waiãpi.

12 As traduções oferecidas partem de uma análise do uso waiāpi desses termos nos contextos de julgamento da diferença aqui discutidos, e não de uma comparação com interpretaçōes de estudiosos de outras línguas tupi-guarani. Nos contextos em pauta, é o processo temporal e a possibilidade de transição de uma posição a outra que essas glosas enfatizam.

13 Quando uso o termo "criar", refiro-me aos procedimentos que os Waiāpi descrevem, entre outros, como -movia, referindo-se a todo um elenco de cuidados corporais e alimentares que irão "fazer crescer" uma pessoa (seja ela humana ou não) para que se torne "como a gente" e passe a ser referida como cria (reminô) de quem cuidou dela.

14 Conferir Waiwai e Kumai, que apreciavam imensamente dialogar a respeito desses procesos: "Fomos nós que fizemos apã, os antigos queriam que fossem bravos - sim, foram os nossos antepassados que os envenenaram" (no caso, o veneno se refere à capacidade de agressão).

15 Conferir as distinçôes de gente que nasce dos vermes de cabas e abelhas diferentes nas narrativas relativas aos "animais sedutores", transcritas em Gallois (1998).

16 Sobretudo se consideramos que o processo continua, podendo-se criar gente "como nós" que será aglutinada ao estoque de janekwer, do mesmo modo que se pode continuar eliminando definitivamente inimigos, que passam a ser referidos como apã'wer.

17 Principalmente por causa da figura emblemática de Raoni, conhecido pelas imagens de vídeo.

18 Como os próprios Waiãpi afirmam, tais posiçōes são inviáveis, mesmo que os nãoíndios esperem isso deles. "Eu já disse (aos não-índios) que Waiāpi não consegue falar com todos", afirmava recentemente o presidente do Conselho Apina aos representantes de agentes de assistência que cobravam dele a expressão de um consenso "dos Waiāpi". 
Revista de Antropologia, São Paulo, USP, 2007, v. 50 No 1.

19 Esse formato de relações em rede - que viabiliza os procedimentos de aproximação e distanciamento, de reclassificação de parentes e afins - não é apenas "exterior" aos Waiápi, mas principalmente "interior" a sua vida social. Entre as parentelas desse povo, tensōes se manifestam constantemente por meio de acusaçôes de agressão xamanística, que aproximam ou distanciam famílias entre si. Nesse movimento, o termo parente encontra seu lugar, como atesta este desabafo de um chefe de aldeia: "Antigamente não tinha cobra aqui. Tinha muito pajé. Hoje tem eu que tem pajé mas quebrou meu espelho no mato, pajé Aparai mandou pedra. Agora não enxergo muito bem. Aparece surucucu direto aqui, porque o pessoal do Aramirã não gosta daqui, diz que missionário fica manipulando a gente [...] pessoal do Taitetuwa, do Mariry diz que a gente ficou tudo doido, não gosta da gente. A gente é sozinho mesmo. O pessoal do Taitetuwa não pára aqui para conversar, tomar caxiri. Aqui não tem esse negócio de parente! Aqui a gente é sozinho, não tem parente" (Ytuwasu, 1999, in Rosalen).

20 O formato que os Waiāpi consideram adequado nas relaçôes interpessoais, que envolvem formas de tratamento, etiquetas comportamentais, expressóes verbais e corporais etc. (cf. Dias, 1998).

\section{Bibliografia}

ALBERT, B.

1988 "La fumée du métal. Histoire et représentations du contact chez les Yanomami (Brésil)", L'Homme, pp. 106-7, (Le mythe et ses métamorphoses).

BAHBA, $\mathrm{H}$

1998 O local da cultura, Belo Horizonte, Editora da UFMG.

BARTH, F.

1987 Cosmologies in the Making: a Generative Approach to Cultural Variation in Inner New Guinea, Cambridge University Press.

CLIFFORD, J.

1997 Routes. Travel and Translation in the Late Twentieth Century, Harvard University Press. 
Dominique T. Gallois. Gêneses Waī̄PI, entre Diversos e Diferentes

DESCOLA, P.

1996 "Constructing Natures: Symbolic Ecology and Social Practice", in DESCOLA $\&$ PALSSON, Nature and Society, Routledge.

FAJARDO, G. D.

1999 "Contato interétnico e vivência da alteridade entre os Tiriyó: alcances e limites das teorias vigentes”, comunicação no GT Etnologia Indígena, Anpocs.

GALLOIS, D. T.

1985 "Índios e brancos na mitologia waiāpi: da separação dos povos à recuperação das ferramentas", Revista do Museu Paulista, vol. 30.

1986 Migração, guerra e comércio, os Waiāpi, Departamento de Antropologia, FFLCH-USP.

1988 O movimento na cosmologia waiāpi: criação, expansão e transformação do universo, tese de doutorado.

1989 "O discurso waiāpi sobre o ouro: profetismo moderno", Revista de Antropologia, vol. 30.

1993a "Jane Ayvukasi: discurso político e auto-representação waiãpi”, in ALBERT \& RAMOS (org.), Pacificando o branco, no prelo.

1993b Mairi revisitada: a reintegração da Fortaleza de Macapá na tradição oral dos Waiāpi, NHII-USP/Fapesp.

1995 "Diálogo entre povos indígenas: a experiência de dois encontros mediados pelo vídeo", Revista de Antropologia, vol. 38(1).

1998 "Brazil: the Case of the Waiãpi", in GRAY, A.; PARADELLA, A.; NEWING, H. (eds.), From Principle to Practice: Indigenous Peoples and Biodiversity Conservation in Latin America, Copenhagen, IWGIA, Forest People Programme/AIDESEP.

1999 "Participação indígena: a experiência da demarcação waiāpi", in Demarcaçôes de terras indígenas na Amazônia, Brasília, PPTAL/Funai/GTZ.

$2000 \quad$ "Sociedades indígenas em novo perfil: alguns desafios", Travessia, Revista do Migrante, ano XIII, n. 36, jan.-abr.

HANNERZ, U.

1992 "The Global Ecumene as a Network of Networks", in KUPER, A. (ed.), Conceptualizing Society, Routledge.

1997 "Fluxos, fronteiras, hibridos: palavras-chave da antropologia transnacional", Mana, (3) 1. 
Revista de Antropologia, São Paulo, USP, 2007, v. 50 oo 1.

HENLEY, P.

1996 South American Indians Models in the Amazonian Lowlands.

HILL, J. (ed.)

1996 History, Power and Identity. Ethnogenesis in the Americas, 1492-1992, Iowa, University of Iowa Press.

HOWARD, C.

1993 "Pawana: a farsa dos visitantes entre os Waiwai da Amazônia", in CARNEIRO DA CUNHA, M. \& VIVEIROS DE CASTRO, E. (orgs.), Amazônia: etnologia e história indigena, São Paulo, NHII-USP.

LIMA, T. S.

1998 Por uma teoria da distinção natureza e cultura na cosmologia juruna, comunicação no GT Etnologia Indígena, Anpocs.

MELATTI, J. C.

1997 Indios da América do Sul: áreas etnográficas, Brasília, dat.

MENGET, P.

1985 "Jalons pour une étude comparative (Dossier: Guerre, société et vision du monde dans les basses terres de l'Amérique du Sud)", Journal de la Société des Américanistes, vol. LXXI.

NHII-USP

2001

Quarto relatório da Pesquisa Temática "Sociedades indígenas e suas fronteiras na região Sudeste das Guianas", coordenação de Dominique T. Gallois, ms.

OVERING, J.

1991 "A estética da produção: o senso de comunidade entre os Cubeo e os Piaroa", Revista de Antropologia, vol. 34.

RIVIÈRE, P.

1984 Individual and Society in Guiana. A Comparative Study of Amerindian Social Organization, Cambridge University Press.

1995 "AAE na Amazônia”, Revista de Antropologia, vol. 38(1). 
Dominique T. Gallois. Gêneses WaiĀPi, entre diversos e Diferentes

\section{SAHLINS, M}

$1990 \quad$ Ilhas de história, Rio de Janeiro, Zahar.

1997 "O 'pessimismo sentimental' e a experiência etnográfica: porque a cultura não é um 'objeto’ em via de extinção (partes 1 e 2)”, Mana, vol. 3(1) e 3(2).

SMITH, R. C.

1991 "A Search for Unity within Diversity: Peasant Unions, Ethnic Federations and Indianist Movements in the Andean Republics", in MACDONALD, T. (ed.), Native Peoples and Economic Development, Six Case Studies from Latin America, Cultural Survival.

SZTUTMAN, R.

2000 Caxiri, a celebração da alteridade. Ritual, comunicação na Amazônia indigena, dissertação, PPGAS, USP

\section{VIVEIROS DE CASTRO, E. B.}

1993 "Estórias ameríndias", Novos Estudos Cebrap, vol. 36.

1996 "Os pronomes cosmológicos e o perspectivismo ameríndio", Mana, vol. 2(2). 
Revista de Antropologia, São Paulo, USP, 2007, v. 50 No 1.

ABSTRACT: Based on the revision of material registered with the Wajăpi of Amapá in different situations of interlocution, this article seeks to comprehend the construction of differences based on the native models concerning humanity. The indigenous reflections and their use of social distance markers are treated as "ethno gênesis", in the plural. In these cases, such processes are not limited to the construction of identities in the colonial encounter, but are dynamically transformed in the contexts of social networks.

KEY-WORDS: Guianas, social networks, narratives, native models.

Recebido em novembro de 2007, aceito em dezembro de 2007. 